\title{
A stochastic model of domestic water consumption and greywater generation in the Al Ain city
}

\author{
$\underline{\text { R. K. Chowdhury }}$ \\ Department of Civil and Environmental Engineering, United Arab Emirates University \\ United Arab Emirates \\ Email: RezaulKabir@uaeu.ac.ae
}

\begin{abstract}
The sources of urban water in the United Arab Emirates are groundwater, desalinated water and treated wastewater. About three-quarters of desalinated water are used for irrigation to amenity plantations. Water consumption in major cities varies between 170 and 200 liter per capita per day (Lpcd) in flats and between 270 and $1760 \mathrm{Lpcd}$ in villas. Irrigation to roadside plants, home gardens and to recreation areas has been increasing in the region with the rapid growth of its urban development. Diversification of water sources and water demand reduction are therefore considered two vital tools for the security of urban water supplies. Currently about $98 \%$ of municipal wastewater are centrally collected through an efficient sewerage networks and then treated for reuse to provide irrigation to roadside plantations. The treated wastewater is not conveyed to houses because of the necessity of dual reticulation systems. Reuse of greywater (household wastewater except from kitchen and toilet) for non-potable consumptions (gardening and toilet flush) can be an alternative. The objective of this study is to investigate the potential for decentralized (individual houses) harvesting and reuse of greywater in Al Ain city for non-potable consumptions. An attempt has been undertaken to estimate domestic water consumptions and greywater generation in the city. The frequency and water volume of personal water uses (shower, ablution, toothbrush, hand wash, face wash, toilet flush) and family water uses (laundry, dish wash, home clean, car wash, pet wash, gardening) were estimated from 100 homes randomly distributed across the city. Their probability distributions were fitted using the normal, log-normal, gamma and logistic distributions. The estimated average greywater generation rate was found to be $195 \mathrm{Lpcd}$. For personal water uses, highest consumption was observed in shower, toilet flush and ablution accordingly. About $70 \%$ respondents considered greywater can be reused for gardening. Considering the high variability of water uses frequency and time requirements, the probabilistic model is recommended for greywater quantitative analysis.
\end{abstract}

Keywords: Water consumption, greywater generation, water uses frequency, probability distribution. 


\section{INTRODUCTION}

United Arab Emirates (UAE) is one of the most water scarce countries but their water consumption rate is significantly high. In the Emirate of Abu Dhabi (EAD), water consumption in flats ranges between 170 and 200 liters per capita per day (Lpcd) and between 270 and 1,760 Lpcd in villas (Abu Dhabi Water Resources Master Plan, 2009). The rapid population growth and the anticipated climate change impact will worsen this water stresses across the country. Security of EAD's urban water resources requires augmentation of water supply sources and water demand reduction. Greywater reuse is therefore becoming a popular alternative urban water resource. About $98 \%$ of wastewater generated from households in EAD is centrally collected through an efficient sewerage networks and then treated for reuse in the roadside plantation irrigation systems. Treated wastewater is not reused for domestic purposes because of high expenses of dual reticulation system. In this study, attempt was made to investigate potential of greywater reuse in the Al Ain city for non-potable consumption purposes such as toilet flushing and gardening.

Since 1960s, water uses in EAD has increased rapidly. This is because of desert greening policies of the government and the expansion of agriculture into the lands surrounding traditional oases. More than 300,000 ha of the desert had been planted with trees, irrigated mostly from groundwater, and more recently supplemented by desalinated water (Abu Dhabi Water Resources Master Plan, 2009). Water consumption rate in UAE is higher than most developed countries (150 - 250 liter per capita per day). According to the Plan Abu Dhabi 2030: The Urban Structure Framework Plan (Abu Dhabi Urban Planning Council, 2007), population of EAD will be more than three millions by 2030 and tourism will be increased to almost 8 million visits per year (currently there are 1.8 million visits per year). This additional population will create tremendous pressure on existing water resources and water infrastructures. Currently, two thirds of EAD's water resources are used in agriculture and forestry. Agricultural water demand around Al Ain (a city in EAD) and Liwa exceeds the natural recharge capacity of the groundwater reservoir and their groundwater levels have dropped significantly. Three quarters of desalinated water supplies in EAD are used primarily for vegetation - amenity plantations, home gardening, parks and private households. Therefore, to ensure adequate potable water supply and to reduce freshwater demand is one of the most significant challenges in EAD. As a consequence, the EAD-Environment Agency has prioritized the necessity of improvement of water quantity and quality in EAD; and the Plan Abu Dhabi 2030 has emphasized on sustainable utilization of land and water resources.

The Abu Dhabi Water Resources Master Plan (2009) identified three options to ensure future water supplies (a) demand reduction (b) supply augmentation and (c) a combination of the two. Wastewater and recycled desalinated water collected by the sewer system is a valuable resource in a water scarce country. Currently available modern treatment technologies are capable to treat wastewater and can meet the water quality standards. In EAD, a centralized collection and treatment of domestic and municipal wastewater is followed. Wastewater is collected through a network of $5,100 \mathrm{~km}$ of sewers and $500 \mathrm{~km}$ of rising mains. There are 241 pumping stations to keep the system in flowing condition and a total of 32 treatment units are in operation conditions. They treat about $95 \%$ of wastewater collected by the sewer networks. The average rate of treated sewage effluent (TSE) produced per person served by the Abu Dhabi Sewerage Services Company (ADSSC) is about 130 Lpcd based on a serviced population of 1.4 million. Currently about 35\% of TSE (51 Million cubic meter/year) produced in EAD is disposed of into the Gulf because of the capacity limitations of the TSE dedicated irrigation distribution systems. Domestic water consumption in EAD is about 183 million cubic meter year and the sewers collect about 181 million cubic meter/year. Therefore the efficiency of centralized wastewater collection is $98 \%$, which is an exceedingly efficient management system. About $50 \%$ to $80 \%$ of wastewater constitutes greywater (shower water, ablution water, washing water etc.) which is comparatively less pathogenic than black water (toilet and kitchen wastewater). Current practice of centralized wastewater collection system does not separate greywater and blackwater. It is generally considered that some demand management measures such as increase of water tariffs would primarily affect household's outdoor use of water, little of which is captured by the sewerage system. Therefore increasing tariffs will not necessarily lead to a reduction in wastewater or greywater generation rate (Abu Dhabi Water Resources Master Plan, 2009).

Approximately one fifth of residential water is used for toilet flushing and about one third is for irrigation to amenity vegetation. Though a highly efficient (98\% efficiency) centralized wastewater collection sewer network and treatment plants are available in EAD, end uses of TSE requires development of an expensive distribution network (dual reticulation). This will increase the marginal cost of water supply significantly. That's why a centralized TSE reuse scheme is not economically viable. In some water scarce countries (for example, Australia), decentralized (household level) harvesting and reuse of alternative water resources such as rainwater and greywater shows an economically viable solution for water supply augmentation and 
capable of fulfilling a potable water savings target (Chowdhury et al., 2011, 2012). For example, the south east Queensland Regional Plan (2009) in Australia set a mandatory potable water savings target of 70 kiloliter/household/year in south east Queensland by promoting alternative water resources.

This study is about the potential for decentralized (individual houses) harvesting and reuse of greywater in $\mathrm{Al}$ Ain city for non-potable consumptions. A stochastic method of water consumption and greywater generation from houses located in $\mathrm{Al}$ Ain has been developed in this paper. A questionnaire survey was conducted among 100 residential houses to investigate the nature of water consumptions and their willingness for reuse of greywater. Because of high variability of domestic water consumptions, the stochastic model is useful for water balance modeling and for the estimation of potable water savings potential.

\section{DATA AND METHODS}

A field survey was made to investigate the social attitudes toward water consumption and reusing greywater in the $\mathrm{Al}$ Ain city and to find out a number of parameters through personal interviews. The parameters are living place, family members, number of vehicles, indoor and outdoor water uses, water bills and their opinion about reusing greywater. The number of interviewees was estimated by using Equation (1), which estimates a population based representative sample (Ghisi and Ferreira, 2007).

$$
n \geq \frac{N / \varepsilon^{2}}{\frac{1}{\varepsilon^{2}}+N}
$$

where $n$ is the sample size, $N$ is the population size, and $\varepsilon$ is the sample error (from $1 \%$ to $20 \%$ ). Taking the total population of the city (approximately 0.5 million) including peri-urban areas and assuming a $10 \%$ sample error, one hundred interviews were conducted. The respondents were chosen randomly about $50 \%$ men and 50\% women. The interviews were made at homes, offices, university and in cafeterias. The questions in the interviews included house and garden area, family members, number of vehicles, social acceptance of reusing greywater for toilet flushing and gardening, and frequency of shower, face and hand washing, tooth brushing, clothes and dish washing, house cleaning, and toilet use etc. Equations (2) to (5) were used to estimate the daily water consumption. Greywater generation can be estimated using the Equation (6). Similar type of method was previously applied in Mourad et al. (2011).

$$
\begin{aligned}
& W_{d}=W_{p}+W_{f} \\
& W_{p}=F_{s} Q_{s}+F_{t b} Q_{t b}+F_{h w} Q_{h w}+F_{f w} Q_{f w}+F_{a} Q_{a}+F_{t f} Q_{t f} \\
& W_{f}=\left(F_{l} Q_{l}+F_{d w} Q_{d w}+F_{c} Q_{c}+F_{p} Q_{p}+F_{v} Q_{v}+F_{g} Q_{g}\right) / F M \\
& Q=T F_{R} \\
& G_{w}=F_{s} Q_{s}+F_{t b} Q_{t b}+F_{h w} Q_{h w}+F_{f w} Q_{f w}+F_{a} Q_{a}+\left(F_{l} Q_{l}+F_{c} Q_{c}\right) / F M
\end{aligned}
$$

where $W_{d}$ is the daily water consumption in liter per capita per day (Lpcd), $W_{p}$ is the personal water consumption (Lpcd) and $W_{f}$ is the water consumption within the family (Lpcd); $F_{s}, F_{t b}, F_{h w}, F_{f w}, F_{a}, F_{t f}, F_{l}$, $F_{d w}, F_{c}, F_{p}, F_{v}$ and $F_{g}$ are the daily frequency of using shower, tooth brush, hand wash, face wash, ablution, toilet flush, laundry, dish wash, cleaning, pet water, vehicle cleaning and irrigation to garden, respectively; $Q_{s}, Q_{t b}, Q_{h w}, Q_{f w}, Q_{a}, Q_{t}, Q_{l}, Q_{d w}, Q_{c}, Q_{p}, Q_{v}$ and $Q_{g}$ are the water consumption, in liters, for each use of shower, tooth brush, hand wash, face wash, ablution, toilet flush, laundry, dish wash, home cleaning, pet water, vehicle cleaning and gardening, respectively; $T$ indicates time requirements for water uses in minute and $F_{R}$ indicates flow rate in Liter/minute; and $F M$ is a number of family members.

The time requirements for one event of different personal and family water uses were estimated from a group of twelve volunteers, seven males and five females, having different age classes and marital status. The quantity for each toilet flush was estimated from the volume of toilet tank. The estimated time for other activities other than toilet flushing was multiplied by their flow rates. Average flow rates were measured using a volumetric jar and a stop watch. Finally, probability distribution of frequency of different water uses and their time requirements were performed using four distributions (normal, lognormal, gamma and logistic distributions). Using the best fitted probability distributions at $95 \%$ significance level, daily water consumption and greywater generation in residential premises were generated. 


\section{RESULTS AND DISCUSSION}

\subsection{Water Uses Frequency Analysis}

Statistical characteristics of different water uses per person per day (or week) are shown in Table 1. Probability distributions at 95\% significance level of these variables are shown in Figure 1 . Number of bed rooms and vehicles are best fitted by the lognormal distribution. Numbers of people in houses are best fitted by the gamma distribution. Number of toilet flushes, hand washes, face washes, laundry (per week), dish washes and car washes (per week) are best fitted by the normal, logistic, gamma, normal, gamma and logistic distributions, respectively at the 95\% significance level. All of the houses surveyed were villa type detached house and generally occupy provision for amenity plantation. Average family members of around 12 persons per house and their high variance (21.35) are a representation of cultural practices of joint family (brothers and their families live in the same house along with their grandparents) in the region. In the survey, children of age less than 3 years were not considered. The five times ablution in a day is a religious practice in the region and an average ablution frequency of 4.42 per person per day indicates that some people perform ablution outside of home (at mosque).
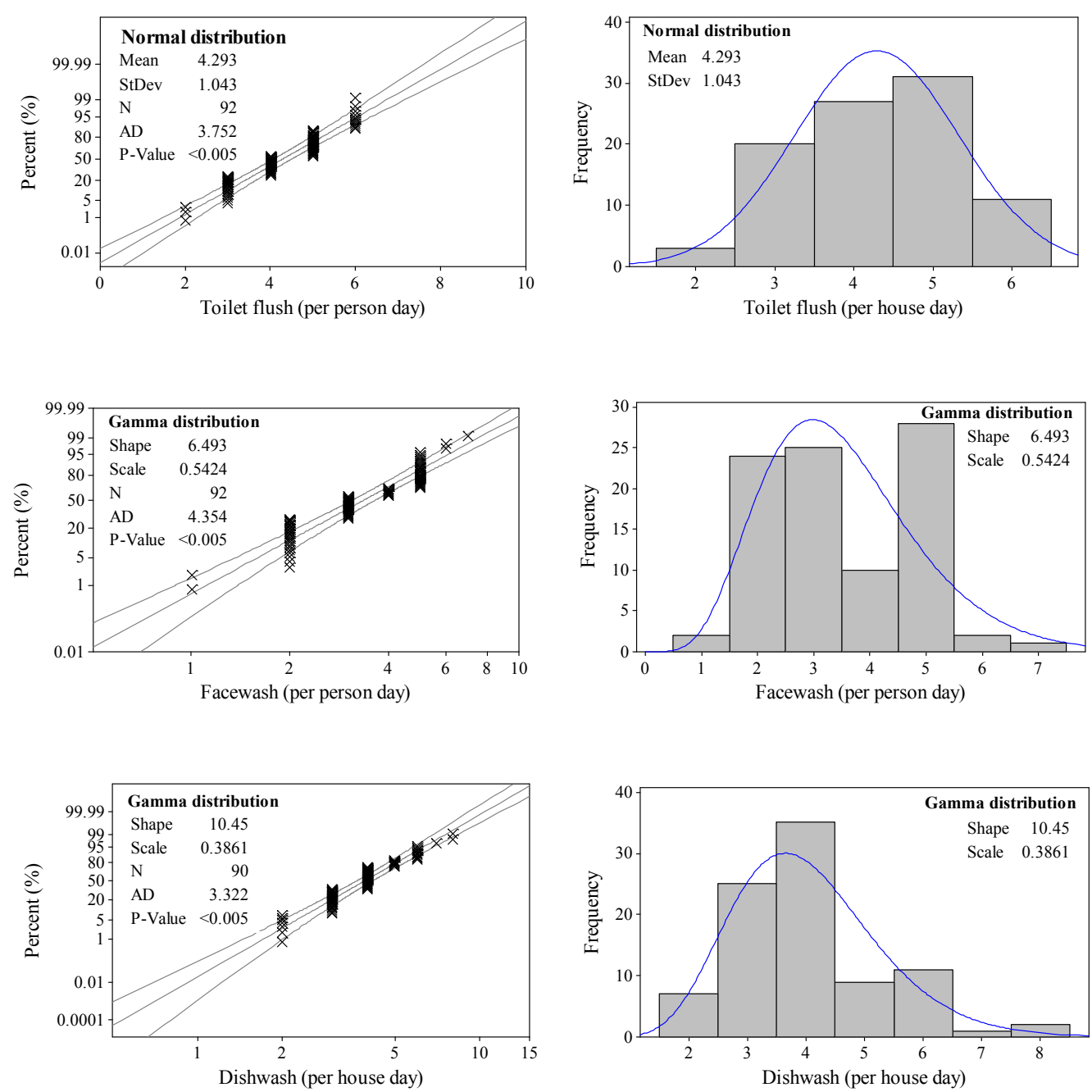

Figure 1: Best fitted probability distributions at 95\% significance level of frequency of water uses (toilet flush, face wash and dish wash are shown) 
Chowdhury R. K., A stochastic model of water consumption and greywater generation in Al Ain

Table 1: Statistical characteristics of frequency of water uses at residential premises in Al Ain

\begin{tabular}{|c|c|c|c|c|c|c|c|c|c|c|c|}
\hline Variable & Mean & St dev & Variance & $\mathrm{CV}$ & Min & Q1 & Median & Q3 & Max & Skewness & Kurtosis \\
\hline Bedroom/house & 6.76 & 2.18 & 4.75 & 32.22 & 2.00 & 5.00 & 6.00 & 8.00 & 12.00 & 0.61 & 0.22 \\
\hline Car/house & 4.41 & 1.81 & 3.27 & 40.96 & 2.00 & 3.00 & 4.00 & 6.00 & 9.00 & 0.81 & -0.01 \\
\hline People/house & 11.60 & 4.62 & 21.35 & 39.82 & 4.00 & 8.00 & 11.00 & 15.00 & 24.00 & 0.41 & -0.31 \\
\hline Shower/p/d & 1.68 & 0.73 & 0.53 & 43.04 & 1.00 & 1.00 & 2.00 & 2.00 & 4.00 & 0.74 & -0.08 \\
\hline Toilet flush/p/d & 4.29 & 1.04 & 1.09 & 24.30 & 2.00 & 3.25 & 4.00 & 5.00 & 6.00 & -0.14 & -0.72 \\
\hline Tooth brush/p/d & 2.15 & 0.65 & 0.42 & 29.97 & 1.00 & 2.00 & 2.00 & 3.00 & 4.00 & 0.10 & -0.04 \\
\hline Hand wash/p/d & 4.71 & 1.52 & 2.32 & 32.37 & 1.00 & 4.00 & 5.00 & 5.00 & 9.00 & 0.47 & 1.19 \\
\hline Face wash/p/d & 3.52 & 1.34 & 1.79 & 38.00 & 1.00 & 2.00 & 3.00 & 5.00 & 7.00 & 0.21 & -1.02 \\
\hline Ablution/p/d & 4.42 & 0.98 & 0.96 & 22.21 & 1.00 & 4.00 & 5.00 & 5.00 & 6.00 & -1.50 & 1.48 \\
\hline Laundry/w & 6.44 & 2.91 & 8.49 & 45.26 & 1.00 & 4.00 & 7.00 & 7.00 & 14.00 & 0.35 & -0.10 \\
\hline Dish wash/d & 4.03 & 1.29 & 1.65 & 31.85 & 2.00 & 3.00 & 4.00 & 5.00 & 8.00 & 0.85 & 0.84 \\
\hline Home clean/d & 1.24 & 0.65 & 0.43 & 52.76 & 0.00 & 1.00 & 1.00 & 2.00 & 3.00 & 1.00 & 1.08 \\
\hline Gardening/d & 1.56 & 0.64 & 0.41 & 41.14 & 1.00 & 1.00 & 1.00 & 2.00 & 4.00 & 1.03 & 1.48 \\
\hline Carwash/w & 2.03 & 1.09 & 1.19 & 53.75 & 1.00 & 1.00 & 2.00 & 3.00 & 5.00 & 1.01 & 0.64 \\
\hline Pet water/d & 0.62 & 1.20 & 1.43 & 191.94 & 0.00 & 0.00 & 0.00 & 1.00 & 5.00 & 2.05 & 3.64 \\
\hline
\end{tabular}

St dev $=$ standard deviation, $C V=$ coefficient of variation, $Q 1=25^{\text {th }}$ percentile, $Q 3=75^{\text {th }}$ percentile, per person per day $=/ \mathrm{p} / \mathrm{d}$, per week $=/ \mathrm{w}$

\subsection{Frequency Analysis of Time Requirements for Water Uses}

Time requirements for different water uses were estimated and their statistical characteristics are shown in Table 2. Their frequency distributions are shown in Figure 2. Time requirements for toothbrush and car wash are best fitted by the logistic distribution whereas hand wash, face wash, shower, ablution and dish wash time requirements are best fitted by the gamma distribution. Time requirements for different personal water uses (shower, hand wash, ablution, for example) are generally depend on cultural practices and on water tariff structure. It is observed from Table 2 that shower and dish wash time are highly variable with an average time of 9.71 and 31.67 minutes and a standard deviation of 4.4 and 4.2 minutes, respectively. This is probably because of variation in people's shower water use practices and variation in dish washing techniques. In most of homes surveyed, there is a hose pipe connection at the garage for car washing and gardening purposes. The car wash time presented in Table 2 indicates the hose pipe running time only.

Table 2: Statistical characteristics of time requirements for different water uses

\begin{tabular}{|c|c|c|c|c|c|c|c|c|c|c|c|}
\hline Variable (minute) & Mean & St dev & Variance & $\mathrm{CV}$ & Min & Q1 & Median & Q3 & Max & Skewness & Kurtosis \\
\hline Toothbrush & 1.55 & 0.82 & 0.67 & 52.77 & 0.39 & 1.08 & 1.44 & 2.00 & 4.00 & 0.74 & 0.96 \\
\hline Hand wash & 1.09 & 0.86 & 0.73 & 78.81 & 0.12 & 0.29 & 1.02 & 2.00 & 3.00 & 0.68 & -0.60 \\
\hline Face wash & 0.87 & 0.69 & 0.47 & 79.03 & 0.13 & 0.21 & 1.02 & 1.08 & 2.03 & 0.57 & -0.89 \\
\hline Shower & 9.71 & 4.40 & 19.38 & 45.33 & 5.01 & 6.32 & 7.73 & 12.72 & 19.22 & 0.90 & -0.44 \\
\hline Ablution & 2.06 & 0.89 & 0.79 & 42.97 & 0.57 & 1.34 & 2.00 & 3.00 & 4.00 & 0.67 & -0.34 \\
\hline Dish wash & 31.67 & 4.20 & 17.65 & 13.27 & 25.00 & 30.0 & 30.0 & 35.0 & 40.00 & 0.60 & 0.20 \\
\hline Carwash & 6.76 & 1.56 & 2.45 & 23.15 & 5.00 & 5.00 & 7.00 & 8.00 & 10.00 & 0.67 & 0.26 \\
\hline
\end{tabular}

St dev = standard deviation, $C V=$ coefficient of variation, $Q 1=25^{\text {th }}$ percentile, $Q 3=75^{\text {th }}$ percentile
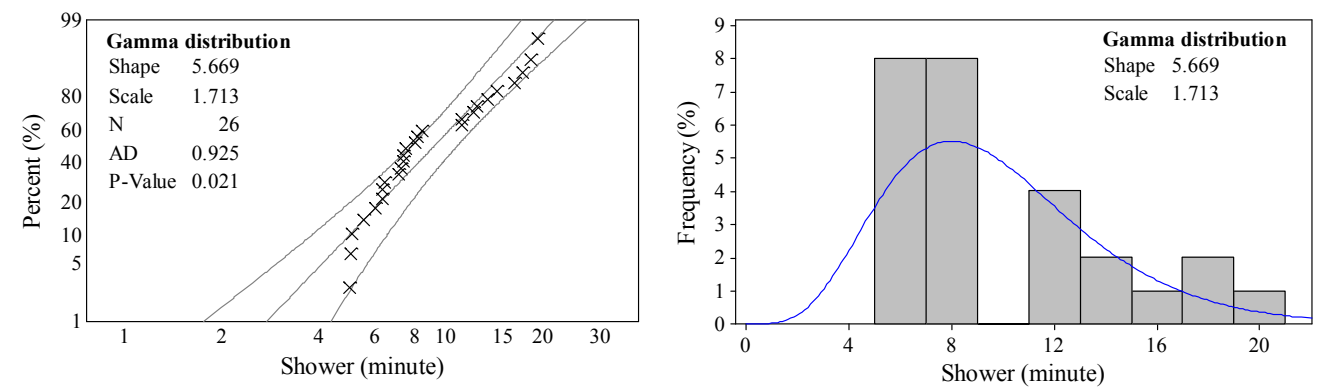

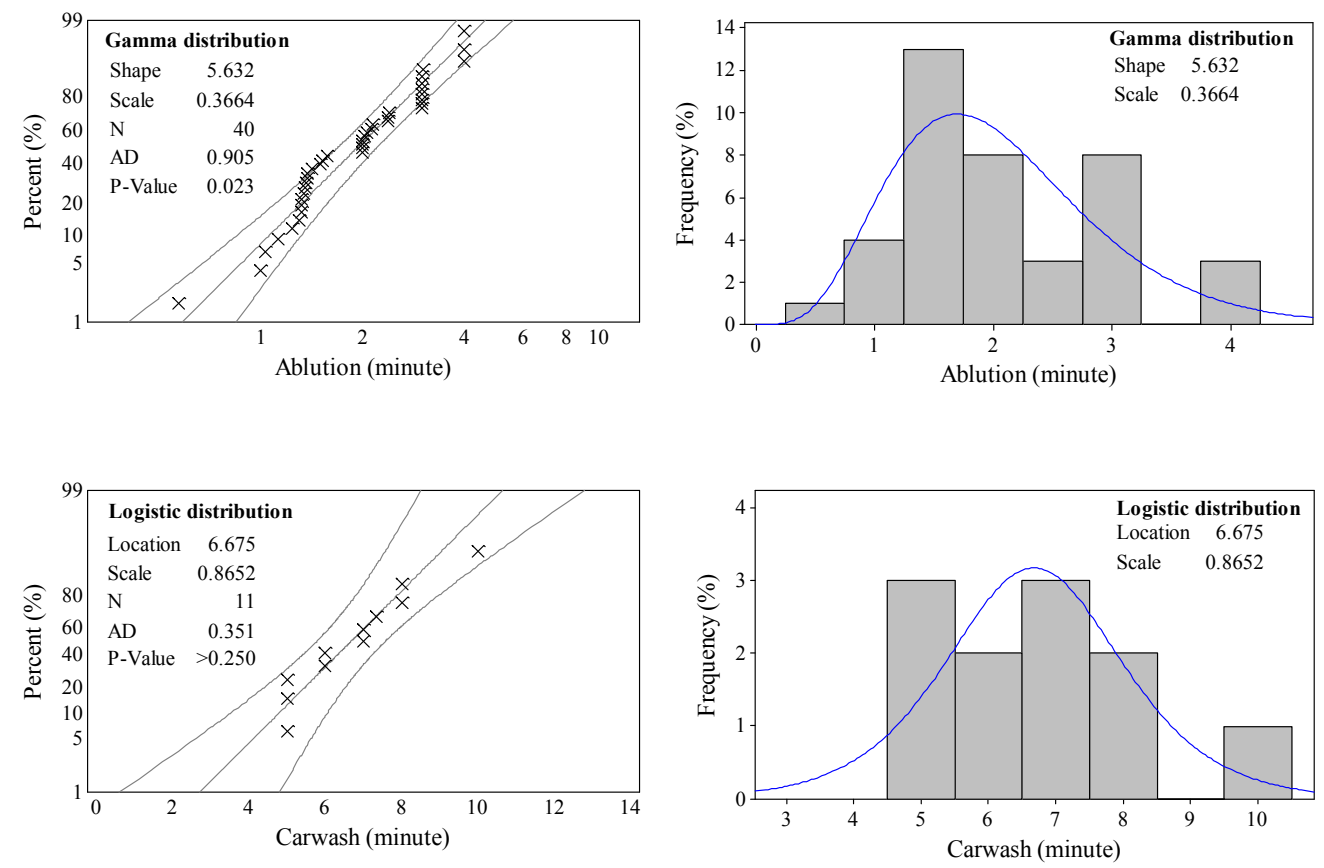

Figure 2: Best fitted probability distributions of time requirements for different water uses at the $95 \%$ significance level (shower, ablution and car wash are shown)

\subsection{Water Consumption and Greywater Generation}

Estimated water consumptions for different water uses are shown in Table 3. Using the Equation (6), estimated average greywater generation rate is found to be $195 \mathrm{Lpcd}$. This estimation is calculated by considering the average time requirements and average frequency of uses of different water uses. For personal water consumptions, it is observed that the highest consumptive uses are shower, toilet flush and ablution, accordingly. The shower consumption is much higher probably because of higher temperature in the region. Average ablution water consumption is found almost equal to toilet flush consumption - in other way it can be said that reuse of ablution water can meet the requirements for toilet flush consumption. For family water consumptions, irrigation (not estimated yet for household cases) and dish wash consumptions are generally higher than other uses. Two types of gardening practices are observed in Al Ain, piped surface irrigation system and hose pipe connection as used for car washing purpose.

Table 3: Estimated water consumption for different water uses

\begin{tabular}{|c|c|c|c|c|c|}
\hline $\begin{array}{c}\text { Personal water } \\
\text { uses }\end{array}$ & $\begin{array}{c}\text { Average time required } \\
\text { (minute) }\end{array}$ & $\begin{array}{l}\text { Flow rate } \\
\text { (L/minute) }\end{array}$ & $\begin{array}{c}\text { Consumption of } \\
\text { water } \\
\text { per use, Q (Liter) }\end{array}$ & $\begin{array}{l}\text { Frequency of use, } \mathrm{F} \text { (per } \\
\text { person day) }\end{array}$ & $\begin{array}{l}\text { Average water consumption } \\
\text { (Lpcd) }\end{array}$ \\
\hline Shower & 9.71 & 5.75 & 56 & 1.68 & 94 \\
\hline Toothbrush & 1.55 & 4 & 6 & 2.15 & 13 \\
\hline Hand wash & 1.09 & 4 & 4 & 4.71 & 19 \\
\hline Face wash & 0.87 & 4 & 3 & 3.52 & 11 \\
\hline Ablution & 2.06 & 4 & 8 & 4.42 & 35 \\
\hline Toilet flush & - & - & 9 & 4.29 & 39 \\
\hline $\begin{array}{l}\text { Family water } \\
\text { uses }\end{array}$ & $\begin{array}{c}\text { Average time required } \\
\text { (minute) }\end{array}$ & $\begin{array}{l}\text { Flow rate } \\
\text { (L/minute) }\end{array}$ & $\begin{array}{c}\text { Consumption of } \\
\text { water } \\
\text { per use, Q (Liter) }\end{array}$ & $\begin{array}{l}\text { Frequency of use, } \mathrm{F} \text { (per } \\
\text { family per day) }\end{array}$ & $\begin{array}{c}* * \text { Average water } \\
\text { consumption (Lpcd) }\end{array}$ \\
\hline Laundry & - & - & 255 & $0.92(6.44$ per week $)$ & 20 \\
\hline Dish wash & 31.67 & 4 & 127 & 4.03 & 44 \\
\hline Carwash & 6.76 & 13.5 & 91 & 0.29 (2.03 per week) & 2 \\
\hline Home clean & - & - & 24 & 1.24 & 3 \\
\hline Irrigation & $*$ & $*$ & $*$ & 1.56 & $*$ \\
\hline Pet water & $*$ & $*$ & $*$ & 0.62 & $*$ \\
\hline
\end{tabular}




\section{CONCLUSION}

Domestic water consumption in $\mathrm{Al}$ Ain is very high, which is because of cultural practices, high temperature in the region and for subsidized water tariff structure to consumers. Based on survey to around 100 villa type houses, it was found that on average about $195 \mathrm{Lpcd}$ of greywater is generated. It was also observed that the ablution water consumption is almost equal to toilet flush water requirements. Therefore there is potential for greywater reuse in $\mathrm{Al}$ Ain. From the questionnaire survey it was found that about $70 \%$ of respondents agreed that greywater can be reused for gardening purposes and about $18 \%$ agreed to reuse greywater for toilet flush purposes.

Because of high variability of different water uses (frequency and time of uses) - a probabilistic model considering probability distribution of different variables in Equations (2) to (6) is recommended rather than considering average generation rate. Sensitivity analysis and comparison with the averaging method is also important. The stochastic method will be followed in order to estimate potable water savings from greywater reuse. The quantity of greywater is considered in this paper, there are some other criteria (greywater quality, irrigation water quality requirements and social acceptance, for example) for the selection of greywater reuse scheme. These criteria are currently investigating in this research project.

\section{ACKNOWLEDGEMENT}

The research is funded by the UAEU-NRF research grant 2013-2014 (grant number: 31N135) “Assessment of decentralized greywater harvesting and reuse opportunity in Al Ain".

\section{REFERENCES}

Abu Dhabi Urban Planning Council (2007). Plan Abu Dhabi 2030: The Urban Structure Framework Plan, Abu Dhabi Urban Planning Council, United Arab Emirates.

Abu Dhabi Water Resources Master Plan (2009). Abu Dhabi Water Resources Master Plan, Environment Agency, Abu Dhabi, United Arab Emirates.

Chowdhury, R., Gardner, T., Gardiner, R., Hartcher, T., Aryal, S., Ashbolt, S., Petrone, K., Tonks, M., Ferguson, B., Maheepala, S. and McIntosh, B. S. (2012). South east Queensland catchment modelling for stormwater harvesting research: Instrumentation and hydrologic model calibration and validation. Technical Report No. 83, Urban Water Security Research Alliance, CSIRO, Australia.

Chowdhury, R., Gardner, T., Laredo, L., McIntosh, B. S., Maheepala, S. and Beecham, S. (2011). Biophysical rules for stormwater harvesting in South East Queensland, Proc. Stormwater Industry Association Queensland State Conference 2011, Gold Coast, Australia.

Ghisi, E. and Ferreira, D. F. (2007). Potential for potable water savings by using rainwater and greywater in a multi-storey residential building in southern Brazil. Build. Environ, 42, 2512-2522.

Mourad, K. A., Berndtsson, J. C. and Berndtsson, R. (2011). Potential fresh water saving using greywater in toilet flushing in Syria. Journal of Environmental Management, 92, 2447-2453.

South East Queensland Regional Plan (2009). South east Queensland regional plan 2009-2031, The state of Queensland (Department of Infrastructure and Planning), Australia. 